NASA/TM-2002-211214

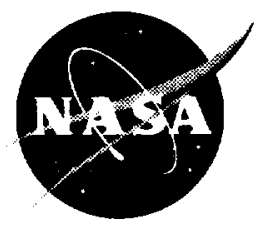

\title{
A Hall Thruster Performance Model Incorporating the Effects of a Multiply-Charged Plasma
}

Richard R. Hofer

QSS Group, Inc., Cleveland, Ohio

Robert S. Jankovsky

Glenn Research Center, Cleveland, Ohio 
Since its founding, NASA has been dedicated to the advancement of aeronautics and space science. The NASA Scientific and Technical Information (STI) Program Office plays a key part in helping NASA maintain this important role.

The NASA STI Program Office is operated by Langley Research Center, the Lead Center for NASA's scientific and technical information. The NASA STI Program Office provides access to the NASA STI Database, the largest collection of aeronautical and space science STI in the world. The Program Office is also NASA's institutional mechanism for disseminating the results of its research and development activities. These results are published by NASA in the NASA STI Report Series, which includes the following report types:

- TECHNICAL PUBLICATION. Reports of completed research or a major significant phase of research that present the results of NASA programs and include extensive data or theoretical analysis. Includes compilations of significant scientific and technical data and information deemed to be of continuing reference value. NASA's counterpart of peerreviewed formal professional papers but has less stringent limitations on manuscript length and extent of graphic presentations.

- TECHNICAL MEMORANDUM. Scientific and technical findings that are preliminary or of specialized interest, e.g., quick release reports, working papers, and bibliographies that contain minimal annotation. Does not contain extensive analysis.

- CONTRACTOR REPORT. Scientific and technical findings by NASA-sponsored contractors and grantees.
- CONFERENCE PUBLICATION. Collected papers from scientific and technical conferences, symposia, seminars, or other meetings sponsored or cosponsored by NASA.

- SPECIAL PUBLICATION. Scientific, technical, or historical information from NASA programs, projects, and missions, often concerned with subjects having substantial public interest.

- TECHNICAL TRANSLATION. Englishlanguage translations of foreign scientific and technical material pertinent to NASA's mission.

Specialized services that complement the STI Program Office's diverse offerings include creating custom thesauri, building customized data bases, organizing and publishing research results ... even providing videos.

For more information about the NASA STI Program Office, see the following:

- Access the NASA STI Program Home Page at http://www.sti.nasa.gov

- E-mail your question via the Internet to help@sti.nasa.gov

- Fax your question to the NASA Access Help Desk at 301-621-0134

- Telephone the NASA Access Help Desk at $301-621-0390$

- Write to:

NASA Access Help Desk NASA Center for AeroSpace Information 7121 Standard Drive Hanover, MD 21076 


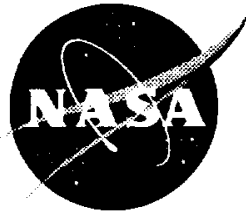

\section{A Hall Thrusiter Performance Model Incorporating the Effects of a Multiply-Charged Plasma}

Richard R. Hofer

QSS Group, Inc., Cleveland, Ohio

Robert S. Jankovsky

Glenn Research Center, Cleveland, Ohio

Prepared for the 37th Joint Propulsion Coriference and Exhibit cosponsored by the AIAf, SAE, AIChE, and ASME Salt Lake City, Utah, July 8-11, 2001

National Aeronautics anc

Space Administration

Glenn Research Center 


\section{Acknowledgments}

The authors would like to thank D. Manzella, P. Peterson, and V. Rawlin for their input and guidance in developing this model. Additionally, we would like to thank M. Domonkos for his comments in preparing this manuscript.

Available from

NASA Center for Aerospace Information 7121 Standard Drive

Hanover, MD 21076
National Technical Information Service 5285 Port Royal Road Springfield, VA 22100

Available electronically at http://gltrs.grc.nasa.gov/GLTRS 


\title{
A Hall Thruster Performance Model Incorporating the Effects of a Multiply-Charged Plasma
}

\author{
Richard R. Hofer \\ QSS Group, Inc. \\ Cleveland, Ohio 44135 \\ Robert S. Jankovsky \\ National Aeronautics and Space Administration \\ Glenn Research Center \\ Cleveland, Ohio 44135
}

\begin{abstract}
A Hall thruster performance moclel that predicts anode specific impulse, anode efficiency, and thrust is discussed. The model is derived as a functio 1 of a voltage loss parameter, an electron loss parameter, and the charge state of the plasma. Experimental data fronı SPT and TAL type thrusters up to discharge powers of $21.6 \mathrm{~kW}$ are used to determine the best fit for model parameters. General values for the model parameters are found, applicable to high power thrusters and irrespective of thruster type. Performance of a $50 \mathrm{~kW}$ thruster is calculated for an anode specific impulse of 2500 seconds or a discharge current of $100 \mathrm{~A}$.
\end{abstract}

\section{Introduction}

The Hall effect thruster (HET) i; a plasma propulsion device that has found application on-board spacecraft for stationkeeping, orbit transfers, orbit raising, and is being considered for interplanetary missions. ${ }^{1-5}$ The combination of high specific impulse $\left(I_{\mathrm{sp}}\right)$ and thrust-topower ratio makes the Hall thruster uniquely qualified to fill such a varied array of missions. In the HET, shown schematically in Figure 1, ions are accelerated by an axial electric field established between a downstream cathode and an upstream anode. An essentially radial magnetic field is, applied in an annular discharge chamber that impedes the motion of migrating electrons due to the crossed electric and magnetic fields creating an azinuthal closed electron drift, the Hall current. Propell int is injected at the anode and collisions in the closed drift region create ions that are then accelerated producing thrust. ${ }^{6-7}$ Commercially developed Hall thrusters typically operate between $50-60 \%$ efficier cy, achieving specific impulses between $1500-2500$ sєconds. ${ }^{8-18}$ Operation below $1500 \mathrm{~s}$ generally results i: intolerable decay in thruster efficiencies $(<35 \%$ efficiency around $1200 \mathrm{~s}$ specific impulse). ${ }^{10}$ Operation above $2500 \mathrm{~s}$ has not been demonstrated for extended reriods of time in the literature, but it is widely believed that the lifetime of a high $\mathrm{I}_{\mathrm{sp}}$ Hall thruster will be signi icantly less due to the production of multiply-charged ions resulting from the higher voltages encountered in the discharge chamber.

The NASA Hall thruster progam is an integrated technology program addressing many propulsion requirements of NASA, DoD, and commercial customers. ${ }^{19}$ The program is implemented at the NASA Glenn Research Center (GRC) by the Power and On-Board Propulsion Division, On-Board Propulsion Branch. As part of this program, investigations of the physical limits of HETs with the goal of extending the operational envelope are being conducted. One way of gaining insight into these limits is through the development of an analytical model that captures the relevant trends of the physical processes in question. To this end, a performance model was developed at NASA GRC. The model predicts thrust, anode specific impulse, and anode efficiency while incorporating the effects of a multiply-charged plasma. Free parameters in the model are found that best fit the experimental data from existing high power $(>3 \mathrm{~kW})$ HETs. This approach decreases the uncertainty when predicting the performance quantities for HETs with power levels approaching $50 \mathrm{~kW}$. Predicting the performance at 50 $\mathrm{kW}$ is of interest due to current NASA efforts to design and fabricate thrusters at this power level.

Other researchers have developed methods for predicting the performance trends of an HET. These range from simple correlations between theoretically obtainable values and experimental results. ${ }^{20}$ to more complex models derived from dimensionless scaling. ${ }^{21-22}$ More recently, researchers at Space Power Inc. (now Pratt \& Whitney) ${ }^{16}$ and the Busek $\mathrm{Co}^{17}$ have almost simultaneously developed essentially identical two parameter models that predict the performance quantities. These efforts have demonstrated the 
successful application of the model to thrusters from the same manufacturer. Values used in the models for the parameters have also roughly compared for power levels above $3 \mathrm{~kW}$. The model presented here builds on the work of previous researchers by adding the extra parameters associated with a multiply-charged plasma, and determining model parameters applicable to a range of high power HETs.

\section{Model Equations}

The goal of the model is to derive equations for the performance quantities thrust, anode specific impulse, and anode efficiency. The derivation begins with the standard definitions in Equations 1-3.

$$
\begin{aligned}
& T=\dot{m}_{a} v_{e} \\
& I_{s p}=\frac{T}{\dot{m}_{a} g} \\
& \eta=\frac{P_{J e t}}{P_{D}}=\frac{\frac{1}{2} T v_{e}}{I_{D} V_{D}}=\frac{T^{2}}{2 \dot{m}_{a} P_{D}}
\end{aligned}
$$

Equations 1-3 neglect cathode flow rate, magnet power, power processing unit (PPU) efficiency, and other parasitic losses that may exist in a propulsion system. This approach is mandated by the variability in design approaches of the various thrusters, i.e. some thrusters have more optimized cathodes, more efficient magnetic circuits, etc. For thrusters with discharge powers larger than $1 \mathrm{~kW}$, typically cathode flow rate is $4-8 \%$ of the total flow rate, ${ }^{8,9,14,16}$ magnet power is $1-4 \%$ of the total input power, ${ }^{9}$ and PPU efficiencies are $90-95 \%{ }^{23,24}$

Any differences between the two major types of HETs were neglected in the derivation of the performance equations. These are the stationary plasma thruster (SPT), which is characterized primarily by a ceramic discharge chamber, and the anode layer thruster (TAL), which is characterized primarily by a metallic discharge chamber. Although differences do exist between SPTs and TALs, their performance quantities are equivalent for thrusters of the same discharge voltage and current. $^{13}$

\section{Singly-Charged Plasma Model}

In an ideal thruster, the discharge voltage is the applied potential through which an ion would be accelerated. However, cathodes typically float between 10-30 V below spacecraft ground ${ }^{9,13-16}$ and the plasma potential around one meter downstream of the exit will still be 5$10 \mathrm{~V}$ above spacecraft ground. ${ }^{25-26}$ Both of these effects lower the maximum accelerating potential that an ion can be accelerated through. Further, because ions are created in the discharge chamber at different axial locations, the plasma exhaust from HETs has a spread in ion velocities, ${ }^{27-28}$ as each ion is accelerated by the voltage drop corresponding to where it was created. The average exit velocity for the thruster as a whole is also affected by the charge state of each ion and the ion beam divergence. To take into account all of these considerations, an average accelerating voltage, $\mathrm{V}_{\mathrm{A}}$, and a voltage loss parameter, $\Delta \mathrm{V}$, are defined. The sum of these quantities is simply the discharge voltage, given by Equation 4.

$V_{D} \equiv V_{A}+\Delta V$

In the HET, ions are accelerated electrostatically. ${ }^{7}$ The average exhaust velocity can then be found through energy conservation, assuming the initial neutral velocity of the propellant is negligible and that the plasma consists solely of singly charged xenon ions.

$\frac{1}{2} m_{x e} v_{e}^{2}=e V_{A}$

Solving for the average exit velocity and substituting Equation 4, a relationship between the exhaust velocity, the discharge voltage, and the voltage loss parameter is found.

$v_{e}=\sqrt{\frac{2 e V_{A}}{m_{x e}}}=\sqrt{\frac{2 e\left(V_{D}-\Delta V\right)}{m_{x e}}}$

It will also be convenient to define the voltage loss parameter defect velocity.

$\Delta u \equiv \sqrt{\frac{2 e \Delta V}{m_{x e}}}$

The discharge current in an HET is the sum of the ion current and electron current.

$I_{D}=I_{B}+I_{e}$

If the electron loss parameter is defined in Equation 9 as the ratio between the electron current and the discharge current, an expression for the ion current can be found by substitution into Equation 8 .

$$
\begin{aligned}
& i \equiv \frac{I_{e}}{I_{D}} \\
& I_{B}=(1-i) I_{D}
\end{aligned}
$$

The electron loss parameter must place an upper limit on the efficiency, since it quantifies how much of the discharge current is electron current. HETs operating above $200 \mathrm{~V}$ typically exhibit electron currents that are $20-30 \%$ of the discharge current. ${ }^{7}$ Assuming that this ratio is immutable and fundamental to HET operation, efficiencies should plateau at $70-80 \%$. 
From mass conservation, the an sde flow rate must be the sum of the mass flow equi ralent ion current and "neutral current"

$\dot{m}_{a}=\frac{m_{w}}{e}\left(I_{B}+I_{n}\right)$

The neutral current is neglected since the ion velocity is typically two orders of magni ude greater than the neutral velocity. This is supported by measurements of the ratio of ion current to the nsutral current in SPTs that show this value may be as high as unity. ${ }^{7}$

$$
\begin{aligned}
& I_{B} \gg I_{n} \text { since } v_{e} \gg v_{n} \\
& \dot{m}_{a} \cong \frac{m_{x e}}{e} I_{B} \cong \frac{m_{x e}}{e}(1-i) I_{D}
\end{aligned}
$$

With the above, it is possible to cerive equations for the performance quantities, which will be denoted by a plus sign to signify that they assum: a plasma of singlycharged ions. Thrust is obtitined by substituting Equations 6 and 13 into Equation 1.

$$
\begin{aligned}
T^{+} & =\dot{m}_{a} v_{\mathfrak{c}}=(1-i) I_{D} \sqrt{\frac{2 m_{x}}{e}\left(V_{L}-\Delta V\right)} \\
& =(1-i) \frac{P_{D}}{V_{D}} \sqrt{\frac{2 m_{w}}{e}\left(V_{D}-\Delta V\right.}
\end{aligned}
$$

Equation 14 provides a way to obtain either constant current or constant power curve; as a function of the discharge voltage and the loss parameters. Anode $I_{s p}$ is now found by substituting Equations 1 and 6 into Equation 2.

$$
I_{s p}^{+}=\frac{T^{+}}{\dot{m}_{a} g}=\frac{\dot{m}_{a} v_{c}}{\dot{m}_{a} g}=\frac{1}{g} \sqrt{\left.\frac{2 c\left(V_{D}\right.}{m}-\Delta V\right)}
$$

The $I_{\mathrm{sp}}$ is only a function of the discharge voltage and voltage loss parameter. This will make it possible to independently fit the voltage loss parameter by considering plots of $I_{s p}$ versus $V_{D}$. Now solve Equation 15 for the inverse of the discl arge voltage, and an alternate form of the thrust as a function of $I_{s p}$ can be derived.

$\frac{1}{V_{D}}=\frac{2 e}{m_{x e}} \frac{1}{\left(I_{s p}^{+} g\right)^{2}+(\Delta u)^{2}}$

\footnotetext{
The definition of a neutral current is simply a matter of convenience. The neutral current as sumes a positive charge of unity, a thermal velocity corresponding to the anode temperature $(\sim 1000 \mathrm{~K})$, and the number density corresponding to the difference bitween the anode flow number density and the ion density.
}

$$
\begin{aligned}
& T^{+}=\dot{m}_{a} v_{c}=\left(\frac{m_{x c}}{e}(1-i) I_{D}\right) g I_{s p}^{+} \\
& =\left(\frac{m_{x e}}{e}(1-i) \frac{P_{D}}{V_{D}}\right) g I_{s p}^{+}
\end{aligned}
$$

Now substitute Equation 16 and simplify.

$$
\begin{aligned}
T^{+} & =\frac{m_{x e}}{e}(1-i) P_{D} g I_{s p}^{+} \frac{2 c}{m_{x e}} \frac{1}{\left(I_{s p}^{+} g\right)^{2}+(\Delta u)^{2}} \frac{\left(I_{s p}^{+} g\right)^{2}}{\left(I_{s p}^{+} g\right)^{2}} \\
& =\frac{2 P_{D}}{g I_{s p}^{+}} \frac{(1-i)}{1+\left(\frac{\Delta u}{g I_{s p}^{+}}\right)^{2}}
\end{aligned}
$$

In the final form of Equation 18 maximum thrust occurs at the $I_{\mathrm{sp}}$ corresponding to the defect velocity. That is, maximum thrust is obtained when the condition in Equation 19 is met.

For maximum thrust, $\Delta u=g I_{s p}^{+}$

Lastly, consider the efficiency. Substitution of Equation 6 and the constant current form of Equation 14 yields the following.

$$
\begin{aligned}
& \eta^{+}=\frac{T^{+} v_{C}}{2 I_{D} V_{D}} \\
& =\frac{(1-i) I_{D}}{2 I_{D} V_{D}} \sqrt{\frac{2 m_{x c}}{e}\left(V_{D}-\Delta V\right)} \sqrt{\frac{2 e\left(V_{D}-\Delta V\right)}{m_{x c}}} \\
& =\left(1-\frac{\Delta V}{V_{D}}\right)(1-i)
\end{aligned}
$$

An alternate form of the efficiency as a function of $I_{s p}$ is obtained by substituting in Equation 18.

$$
\eta^{+}=\frac{2 P_{D}}{g I_{s p}^{+}} \frac{(1-i)}{1+\left(\frac{\Delta u}{g I_{s p}^{+}}\right)^{2}} \frac{g I_{s p}^{+}}{2 P_{D}}=\frac{(1-i)}{1+\left(\frac{\Delta u}{g I s p}\right)^{2}}
$$

In Equation 20, the efficiency is simply a function of the discharge voltage and the loss parameters. This makes it possible to determine a suitable value for the electron loss parameter once the voltage loss parameter has been determined using the $I_{\text {sp }}$ given in Equation 15 . Further, Equation 20 shows how the efficiency asymptotically approaches the value of (1-i) at high discharge voltages. 


\section{Multiply-Charged Plasma Model}

The equations for thrust, $I_{s p}$, and efficiency thus far all assume a plasma consisting of singly-charged ions. This description is not always adequate to describe HET performance behavior, especially at high mass flow rates and high voltages. One possible explanation for this behavior is the effect of a multiply-charged plasma on thruster performance. In order to show how this changes the performance, several new definitions are needed. The following is a generalization of the work presented by Vahrenkamp ${ }^{29}$ to explain multiplycharged effects in ion thrusters. First, consider an ion beam consisting of $n$ charged species (e.g. $\mathrm{Xe}^{+}, \mathrm{Xe}^{2+}$, $\left.\mathrm{Xe}^{3+}, \ldots, \mathrm{Xe}^{\mathrm{n}+}\right)$. Define the fraction of species $\mathrm{i}$ as the ratio of the species density to the beam density.

$\zeta_{i}=\frac{n_{i}}{n_{B}}=$ species fraction

The current of the $i^{\text {th }}$ species, assuming an accelerating voltage of $V_{A}$ will be taken as the following.

$$
\begin{aligned}
& I_{i}=A n_{i} q_{i} v_{e, i}=A n_{i} e Z_{i} \sqrt{\frac{2 e Z_{i} V_{A}}{m_{x e}}} \\
& =A n_{i} Z_{i}^{3 / 2} e^{3 / 2} \sqrt{\frac{2 V_{A}}{m_{x e}}}
\end{aligned}
$$

In the above it is assumed that each species is accelerated through the same accelerating voltage, $V_{A}$. It seems more likely that the higher charge states will be born at axial locations further downstream of the next lowest, but such considerations will be neglected in lieu of adding yet another level of complexity to the model.

The beam current is the sum of each of the currents carried by species i. Summations below are assumed to occur over each species i from 1 to $n$.

$$
\begin{aligned}
& I_{B}=\sum I_{i}=A \sum n_{i} q_{i} v_{e, i} \\
& =A e^{3 / 2} \sqrt{\frac{2 V_{A}}{m_{x e}}} \sum n_{i} Z_{i}^{3 / 2}
\end{aligned}
$$

Making use of Equations 22-24 the current fraction of species $i$ is the ratio of species current to the beam current.

$$
\Omega_{\mathrm{i}}=\frac{I_{i}}{I_{B}}=\frac{\zeta_{i} Z_{i}^{3 / 2}}{\sum \zeta_{i} Z_{i}^{3 / 2}}
$$

The motivation for using Equation 25 stems from experimental results using energy diagnostics that typically yields species fraction information. 27.28 Equation 25 will allow for conversion of those data in the model, where species current fractions are more convenient.

Equations 22-25 make it possible to modify the performance model for the effects of a multiplycharged plasma. First, Equation 6 is modified to account for the average exit velocity of the $i^{\text {th }}$ species as follows.

$$
v_{e, i}=\sqrt{\frac{2 e\left(V_{D}-\Delta V\right)}{m_{x e}}} \sqrt{Z_{i}}
$$

The beam current relationship, Equation 10, remains unchanged. Equation 27 give the mass flow rate of each species, and the anode mass flow rate is the sum of each species flow rate given by Equation 28. The final form for the anode mass flow rate is obtained by substituting Equations 10 and 25.

$$
\begin{aligned}
& \dot{m}_{i} \cong \frac{m_{x e}}{e} \frac{I_{i}}{Z_{i}} \\
& \dot{m}_{a} \cong \sum \dot{m}_{i}=\frac{m_{x e}}{e}(1-i) I_{D} \sum \frac{\Omega_{\mathrm{i}}}{Z_{i}}
\end{aligned}
$$

The quantity given by the summation in Equation 28 is always less than one, so the mass flow rate of a multiply-charged plasma (for the same beam current), is always less than that of a singly-charged plasma.

The thrust of a multiply-charged plasma is given by the sum of the thrust contribution each ion species imparts to the spacecraft. The final form below is derived by substituting Equations 10,25, 26, and 27.

$$
\begin{aligned}
T & =\sum \dot{m}_{i} v_{e, i}=\sqrt{\frac{2 e\left(V_{D}-\Delta V\right)}{m_{x e}}} \frac{m_{x e}}{e} \sum \frac{I_{i}}{Z_{i}} \sqrt{Z_{i}} \frac{I_{B}}{I_{B}} \\
& =(1-i) I_{D} \sqrt{\frac{2 m_{x e}\left(V_{D}-\Delta V\right)}{e}} \sum \frac{\Omega_{i}}{\sqrt{Z_{i}}} \\
& =(1-i) \frac{P_{D}}{V_{D}} \sqrt{\frac{2 m_{x e}\left(V_{D}-\Delta V\right)}{e}} \sum \frac{\Omega_{i}}{\sqrt{Z_{i}}} \\
& =T^{+} \sum \frac{\Omega_{i}}{\sqrt{Z_{i}}}
\end{aligned}
$$

In the final form of Equation 29 above, the thrust of a multiply-charged plasma is simply the singly-charged thrust multiplied by the value of the summation. The quantity given by the summation is always less than unity, which implies that the thrust of a multiplycharged plasma (for the same beam current), is always less than that of a singly-charged plasma. It is important to emphasize that a comparison between a singly- and multiply-charged plasma for the same beam current is being considered. If the comparison is 
between equivalent mass flow rates, then the thrust of a multiply-charged plasma would be greater than the singly-charged version because the average exit velocity of a multiply-charged plasma would be greater.

Considering $I_{\mathrm{sp}}$ now, the mass flow rates do not cancel as they did in Equation 15 becal se of the summations. The derivation below makes use of Equations 10 and 29.

$$
\begin{aligned}
I_{s p} & =\frac{T}{m_{a} g}=\frac{\sum \dot{m}_{i} v_{e, i}}{g \sum \dot{m}_{i}} \\
& =\frac{(1-i) I_{D}}{g} \sqrt{\frac{2 m_{x e}\left(l_{D}-\Delta l\right)}{e}}-\frac{\sum \frac{\Omega_{i}}{\sqrt{Z_{i}}}}{\frac{n}{e}} \frac{x i}{(1-i) I_{D} \sum \frac{\Omega_{i}}{Z_{i}}} \\
& =\frac{1}{g} \sqrt{\frac{2 e\left(V_{D}-\Delta V\right)}{m_{x e}}} \frac{\sum \frac{\Omega_{i}}{\sqrt{Z_{i}}}}{\sum \frac{\Omega_{i}}{Z_{i}}}=I_{s p}^{+} \frac{\sum \frac{\Omega_{i}}{\sqrt{Z_{i}}}}{\sum \frac{\Omega_{\mathrm{i}}}{Z_{i}}}
\end{aligned}
$$

Similarly to the thrust, the multiply-charged version of the $I_{s p}$ is the singly-charged va ue multiplied by the value of the summation given above. Because the quantity given by the summation is always greater than one, the anode $I_{s p}$ of a multiply-cliarged plasma (for the same beam current), is always \& reater than that of a singly-charged plasma.

Finally, efficiency is derived starting with Equation 3 and substituting Equations 28-29.

$$
\begin{aligned}
\eta & =\frac{T^{2}}{2 \dot{m}_{a} P_{D}} \\
& =\frac{\left((1-i) I_{D} \sqrt{\frac{2 m_{x e}\left(V_{D}-\Delta V\right)}{e}} \sum-\frac{2_{i}}{Z_{i}}\right)^{2}}{2 \frac{m_{x e}}{e}(1-i) I_{D} \sum \frac{\Omega_{i}}{Z_{i}} P_{D}} \frac{\left(\sum^{\Omega_{\mathrm{i}}} / \sqrt{Z_{i}}\right)^{2}}{\sum^{\Omega_{\mathrm{i}} / Z_{i}}}=1+\frac{\left(\sum^{\Omega_{\mathrm{i}}} / \sqrt{Z_{i}}\right)^{2}}{\sum^{\Omega_{\mathrm{i}} / Z_{i}}} \\
& =\left(1-\frac{\Delta V}{V_{D}}\right)(1-i) \frac{(1)}{}
\end{aligned}
$$

Again, the multiply-charged version is the singlycharged value multiplied by the value of the summation given above. The summation in the final line of Equation 31 is always less than one, so the efficiency of a multiply-charged plasma (for the same beam current), is always less than that of a singly-charged plasma.

\section{Fitting Model Parameters}

As shown above, the singly-charged model for $I_{\text {sp }}$ is a function of the voltage loss yarameter while the efficiency is a function of both the voltage loss and electron loss parameters. This enables the singlycharged model parameters to be fit sequentially beginning with the $I_{s p}$, next the efficiency, and then the thrust is given based off the previous fits. For the multiply-charged model, species fraction data is taken directly from experiment. This is done because of the large number of free parameters introduced by a multiply-charged plasma. Borrowing from experiment essentially reduces all of the multiply-charged considerations to one lumped parameter. The loss parameters from the singly-charged model are used for the multiply-charged model as well. This is done based on the underlying assumption that the production of multiply-charged ions in the plasma will not change those physical processes in the thruster that determine the loss parameters. Lastly, the final values of the model parameters are determined based on the best fit to thrusters with discharge powers greater than $3 \mathrm{~kW}$, with emphasis on matching data from the $10 \mathrm{~kW} \mathrm{T-220}$ and the TM-50 at a maximum power of $21.6 \mathrm{~kW}$. This approach is taken so that extrapolation of the model to power levels of $50 \mathrm{~kW}$ can be done with greater confidence than if the model was tuned to low power thrusters. Data from thrusters as low as $0.66 \mathrm{~kW}$ will also be used to highlight that the model parameters used here are not generally applicable to low power thrusters.

\section{Multiply-Charged Plasma Parameters}

The multiply-charged model introduces several new quantities as shown in Equations 28-31. Instead of fitting the model to data using arbitrary values, experimental data is used to determine the necessary summations. Experiments by $\mathrm{King}^{27}$ and Gulczinski ${ }^{28}$ at the University of Michigan using a time-of-flight mass spectrometer are used and shown in Table 1. Both researchers obtained ion species fraction data using the instrument. This data can be readily converted into ion current fractions using Equation 25. King's data was taken $0.5 \mathrm{~m}$ downstream of an SPT100 operating at $300 \mathrm{~V}$ and $4.5 \mathrm{~A}$. Gulczinski's data is $0.75 \mathrm{~m}$ downstream from the University of Michigan 5 kW P5 laboratory Hall thruster operating at $300 \mathrm{~V}, 5.2$ A. In the model, the average of the data is taken and used to compute ion current fractions. Although the ion species fractions have been shown to be a function of voltage and flow rate, ${ }^{28}$ the multiply-charged model will neglect such considerations.

\section{Voltage Loss Parameter}

Figure 2 plots data from several thrusters ${ }^{8.18}$ as $\mathbf{I}_{\mathrm{sp}}$ versus discharge voltage. Curves labeled "theory" assume no voltage loss while the "model" curves are those predicted by the model. The voltage loss parameter was fit to $50 \mathrm{~V}$ for both models. The data 
from the nominally $10 \mathrm{~kW} \mathrm{T-220} \mathrm{closely} \mathrm{matches} \mathrm{the}$ singly-charged model over a large range of voltages. Data from the TM- 50 operating at up to $21.6 \mathrm{~kW}$ begins to exceed the theoretical limit for a singly-charged plasma above $500 \mathrm{~V}$, but closely matches the multiplycharged model over a large voltage range. Taken together, the figure demonstrates that both models capture the functional relationships.

Although the voltage loss parameter is tuned for high power thrusters in the figure, data from several low power thrusters are also shown. For example, to match the $I_{\text {sp }}$ of the SPT-70 a voltage loss parameter of $134 \mathrm{~V}$ is needed for the singly-charged model. While the SPT100 requires the parameter to be set to $103 \mathrm{~V}$. Table 2 lists the performance of these two thrusters and the loss parameters necessary to match their performance quantities. The predicted thrust simply falls out once the loss parameters are determined and the agreement is excellent for these thrusters.

\section{Electron Loss Parameter}

Figure 3 plots efficiency versus discharge voltage for several thrusters and the singly- and multiply-charged models. The voltage loss parameter is $50 \mathrm{~V}$ and the electron loss parameter is fit to 0.26 . Other low power thrusters are shown to highlight how the model parameters are fit for high power HETs. The T-220 data exceeds either model at voltages above $300 \mathrm{~V}$, but is less than the models below $300 \mathrm{~V}$. The TM-50 data finds better agreement, following the multiply-charged model the best. It is worth noting that experimentally determined efficiency data typically has an uncertainty of $3-5 \%$, depending on the care with which the data is taken, so much of the data would still fall within the values predicted by the models. Regardless, a more likely explanation of the quality of the fit is that the electron loss parameter is a function of the discharge voltage. The well-known current-voltage characteristic of an HET illustrates why this may true. $\mathrm{Kim}^{7}$ reports that the ion current in an SPT reaches some fraction of the discharge current at voltages above $120 \mathrm{~V}$ and then remains unchanged. However, the discharge current is still changing above $120 \mathrm{~V}$ indicating that the electron current is varying. Accounting for the dependence of the electron loss parameter with discharge voltage is beyond the scope of this work and will be neglected.

\section{Predicting Thrust}

With the loss parameters and the species fractions now set, the thrust can be calculated. Figure 4 plots thrust versus discharge voltage for several constant power and constant current curves. A subset of the thrusters from Figures 2 and 3 is shown for clarity. Shown are data from the T-140, the T-220, and the TM-50. At low power $(3.4 \mathrm{~kW})$ the singly-charged model follows the thruster data the best, at intermediate powers $(10 \mathrm{~kW})$ the thruster data falls in between the singly- and multiply-charged models, and at high power $(21.6 \mathrm{~kW})$ the multiply-charged model follows the thruster data the closest. Overall, the singly- and multiply-charged models are successfully bounding the data up to power levels of $21.6 \mathrm{~kW}$.

\section{High Power Predictions}

With the model parameters determined, extrapolations of the model up to $50 \mathrm{~kW}$ and $100 \mathrm{~A}$ are calculated. Figure 5 plots thrust versus discharge voltage for various constant power and constant current curves. Both versions of the model are included in the figure. although multiply-charged effects are expected to dominate the performance at high power. Depending on the efficacy of the design, the different models should at least bound the performance. The intersection of $50 \mathrm{~kW}$ and $100 \mathrm{~A}$ curves is indicated as well, highlighting the performance of a $500 \mathrm{~V}$ thruster.

Table 3 presents the performance of a $50 \mathrm{~kW}$ thruster operating either at an $I_{s p}$ of $2500 \mathrm{~s}$ or at a discharge current of $100 \mathrm{~A}$. Either approach yields a thrust on the order of $2.5 \mathrm{~N}$ with efficiencies greater than $64 \%$.

\section{Conclusions}

A performance model that includes the effects of a multiply-charged plasma has been developed. The voltage loss parameter was fit to $50 \mathrm{~V}$, the electron loss parameter was fit to 0.26 , and the species fraction data was taken from experiment. Whether the model is used for singly-or multiply-charged plasmas, the predictions bound the existing data for Hall thrusters that are in excess of $3 \mathrm{~kW}$ discharge power. Owing to the success of the model at powers of $3-21.6 \mathrm{~kW}$, extrapolation to a power level of $50 \mathrm{~kW}$ to predict performance has been performed. The resulting calculation yields a thrust on the order of $2.5 \mathrm{~N}$ with efficiencies greater than $64 \%$. 


\section{Nomenclature}

$=$ area, $\mathrm{m}^{2}$

$=$ electron charye, $\mathrm{C}$

$=$ gravitational icceleration, $\mathrm{m} / \mathrm{s}^{2}$

$=$ electron loss rarameter

$=$ ion current, $A$

$=$ discharge cur ent, $\mathrm{A}$

$=$ current of the $i^{\text {th }}$ ion species, $A$

$=$ electron current, $\mathrm{A}$

$=$ neutral currer $\mathrm{t}, \mathrm{A}$

$=$ anode specifi: impulse, $\mathrm{s}$

$=$ singly-charge $\mathrm{d}$ plasma anode specific impulse, $s$

= anode mass flow rate, $\mathrm{mg} / \mathrm{s}$

$=$ mass flow rat $:$ of the $i^{\text {th }}$ ion species,

$\mathrm{mg} / \mathrm{s}$

$=$ mass of a xenon atom, $\mathrm{kg}$

$=$ total number of ion species

$=$ ion number d:nsity, $\mathrm{m}^{-3}$

$=$ number densi $y$ of the $\mathrm{i}^{\text {th }}$ ion species, $\mathrm{m}^{-3}$

$=$ jet power or team power, $W$

= discharge pover, $\mathrm{W}$

$=$ charge of the ${ }^{\text {th }}$ ion species, $\mathrm{eZ}_{\mathrm{i}}$

$=$ thrust, $\mathrm{mN}$

$=$ singly-charge 1 plasma thrust, $\mathrm{mN}$

$=$ accelerating voltage, $\mathrm{V}$

$=$ discharge voliage, $\mathrm{V}$

$=$ average ion exit velocity, $\mathrm{m} / \mathrm{s}$

$=$ average exit velocity of the $i^{\text {th }}$ ion species, $\mathrm{m} / \mathrm{s}$

$=$ average neutril velocity, $\mathrm{m} / \mathrm{s}$

$=$ ion charge state

$=$ defect velocit., $\mathrm{m} / \mathrm{s}$

$=$ voltage loss p irameter, $\mathrm{V}$

$=$ anode efficier cy

$=$ singly-charged plasma anode efficiency

$=$ species currer $t$ fraction of the $i^{\text {th }}$ ion species

$=$ species fractic $n$ of the $i^{\text {th }}$ ion species

\section{References}

1. Oleson, S. R., "Electric Propulsion for Low Earth Orbit Communications Satellites," IEPC-97-102, 25th International Electric Propulsion Conference, Cleveland, OH, Aug 24-28, 1997.

2. Oleson, S. R., Myers, R. M., "Advanced Propulsion for Geostationary Orbit Insertion and Noith-South Station Keeping," Journal of Spacecraft and Rockets, Vol. 34, No. 1, pp. 22-28, Jan-Feb 1997.

3. Oleson, S. R., "Advanced On-Board Propulsion for RLV Launched Spacecraft," IEPC-99-185, $26^{\text {th }}$ International Electric Propulsion Conference, Kitakyushu, Japan, October 17-21, 1999.

4. Gefert, L. P., Hack, K. J., "Options for the Human Exploration of Mars Using Solar Electric Propulsion," AIP Conference Proceedings, No. 458, pp. 1275-1280, STAIF-99, Nov 1999.

5. Oleson, S. R., Sankovic, J. M., "Advanced Hall Electric Propulsion for Future In-Space Transportation," NASA TM-2001-210676.

6. Kaufman, H. R., "Technology of Closed-Drift Thrusters," AlAA Journal, Vol. 23, No. 1, January, 1985, pp. 78-87.

7. Kin, V., "Main Physical Features and Processes Determining the Performance of Stationary Plasma Thrusters," Journal of Propulsion and Power, Vol. 14, No. 5, Sept-Oct, 1998, pp. 736-743.

8. Jacobson, D., Jankovsky R., "Performance Evaluation of a $50 \mathrm{~kW}$ Hall Thruster." AIAA-990457, $37^{\text {th }}$ Aerospace Sciences Meeting and Exhibit, Reno, NV, Jan 11-14, 1999.

9. Jankovsky, R. S., McLean, C., McVey, J., "Preliminary Evaluation of a $10 \mathrm{~kW}$ Hall Thruster," AIAA-99-0456, $37^{\text {th }}$ Aerospace Sciences Meeting and Exhibit, Reno, NV, Jan 1114, 1999.

10. Kim, V., Kozlov, V., Lazurenko, A., Popov, G., Skrylnikov, A., Clauss, C., Day, M., Sankovic, J., "Development and Characterization of Small SPT," AIAA-98-3335, 34 th Joint Propulsion Conference, Cleveland, OH, July 13-15, 1998. 
11. Kim, V., Grdlichko, D., Kozlov, V., Lazurenko, A., Popov, G., Skrylnikov, A., Day, M., "SPT-115 Development and Characterization," AIAA-99$2568,35^{\text {th }}$ Joint Propulsion Conference, Los Angeles, CA, June 20-24, 1999.

12. King, D., Tilley, D, Aadland, R., Nottingham, K., Smith, R., Roberts, C., Hruby, V., Pote, B., Monheiser, J., "Development of the BPT Family of U.S.-Designed Hall Current Thrusters for Commercial LEO and GEO Applications," AIAA98-3338, 34th Joint Propulsion Conference, Cleveland, OH, July 13-15, 1998.

13. Manzella, D. H., Sankovic, J. M., "Hall Thruster Ion Beam Characterization," AIAA-95-2927, $31^{\text {st }}$ Joint Propulsion Conference, San Diego, CA. July 10-12, 1995.

14. Manzella, D., Hamley, J., Miller, J., Clauss, C., Kozubsky, K. Gnizdor, R., "Operational Characteristics of the SPT-140 Hall Thruster," AIAA-97-2919, 33 ${ }^{\text {rd }}$ Joint Propulsion Conference, Seattle, WA, July 6-9, 1997.

15. Mason, L.S., Jankovsky, R.S., Manzella, D.H., "1000 Hours of Testing on a 10 Kilowatt Hall Effect Thruster," AlAA-2001-3773, 37 ${ }^{\text {th }}$ Joint Propulsion Conference, Salt Lake City, UT, July 811,2001 .

16. McLean, C. H., McVey, J.B., Schappell, D.T., "Testing of a U.S.-Built HET System for Orbit Transfer Applications," AIAA-99-2574, 35 $5^{\text {th }}$ Joint Propulsion Conference, Los Angeles, CA, June 2024, 1999.

17. Pote, B., Hruby, V., Monheiser, J., "Performance of an $8 \mathrm{~kW}$ Hall Thruster," IEPC-99-080, $26^{\text {th }}$ International Electric Propulsion Conference, Kitakyushu, Japan, October 17-21, 1999.

18. Sankovic, J. M., Manzella, D. H., Osborn, M. F., "RHETT2/EPDM Development Testing," IEPC97-102, 25th International Electric Propulsion Conference, Cleveland, OH, Aug 24-28, 1997.

19. Jankovsky, R. S., Jacobson, D. T., Mason, L. S., Rawlin, V. K., Mantenieks, M. A., Manzella, D. H., Hofer, R. R., Peterson, P. Y., "NASA's Hall Thruster Program," AIAA-2001-3888, 37 ${ }^{\text {th }}$ Joint Propulsion Conference, Salt Lake City, UT, July 8$11,2001$.

20. Grishin, S. D., Erofeev, V. S., Zharinov, A. V., Naumkin, V. P., Safronov, I. N., "Characteristics of a Two-Stage Ion Accelerator with an Anode Layer," Journal of Applied Mathematics and Technical Physics, No. 2, pp. 28-36, Mar-Apr 1978.

21. Bugrova, A. I., Maslennikov, N. A., Morozov, A. I. "Similarity Laws for the Global Properties of a Hall Accelerator," Soviet Physics: Technical Physics, Vol. 36, No. 6, pp. 612-615, 1991.

22. Domonkos, M. T., "Hall Thruster Scaling," Internal NASA Memorandum, Sept. 2000.

23. Skelly, P. T., Kay, R. J., "RHETT/EPDM Power Processing Unit," IEPC-97-104, 25th International Electric Propulsion Conference, Cleveland, $\mathrm{OH}$, Aug 24-28, 1997.

24. Declercq, H., Bourguignon, E., Scalais, T., Digoin, J. J., "Power Processing Unit for Stationary Plasma Thruster," IEPC-99-059, 26 ${ }^{\text {th }}$ International Electric Propulsion Conference, Kitakyushu, Japan, October 17-21, 1999.

25. King, L. B., Gallimore, A. D., Marrese, C. M., "Transport-Property Measurements in the Plume of an SPT-100 Hall Thruster," Journal of Propulsion and Power, Vol. 14, No. 3, pp. 327-335, May-June 1998.

26. Keidar, M., Boyd, I. D., "Effect of a Magnetic Field on the Plasma Plume from Hall Thrusters," Journal of Applied Physics, Vol. 86, No. 9, Nov. 1, 1999.

27. King, L. B., Gallimore, A. D., "Mass Spectral Measurements in the Plume of an SPT-100 Hall Thruster," Journal of Propulsion and Power, Vol. 16, No. 6, Nov-Dec 2000, pp. 1086-1092.

28. Gulczinski, F. S., Gallimore, A.D., "Near-Field Ion Energy and Species Measurements of a $5-\mathrm{kW}$ Hall Thruster," Journal of Propulsion and Power, Vol. 17, No. 2, Mar-Apr 2001, pp. 418-427.

29. Vahrenkamp, R. P., "Measurement of Double Charged Ions in the Beam of a $30-\mathrm{cm}$ Mercury Bombardment Thruster," AIAA-73-1057, AIAA $10^{\text {th }}$ Electric Propulsion Conference, Lake Tahoe, NV, Oct 31 - Nov 2, 1973.

30. King, L.B., "Transport-property and Mass Spectral Measurements in the Plasma Exhaust Plume of a Hall-effect Space Propulsion System," Ph.D. Dissertation, University of Michigan, 1998. 


\begin{tabular}{|c|c|c|c|c|c|c|c|c|c|c|}
\hline & & & & & & & \multicolumn{4}{|c|}{ Important Summations } \\
\hline & & & & & & & $\Gamma \frac{\Omega_{i}}{n_{1}}$ & $\Gamma \Omega$ & $2 \sqrt{\sqrt{Z_{i}}}$ & $2^{3} \sqrt{Z}$ \\
\hline & \multicolumn{3}{|c|}{ Species Frictions } & \multicolumn{3}{|c|}{ Species Current Fractions } & $Z_{i}$ & $-\sqrt{Z}$ & $\Gamma^{\Omega_{2}}$ & $\Gamma \Omega$ \\
\hline & $x_{e+}^{+}$ & $\mathrm{Xe2}-$ & $\mathrm{Xe} 3+$ & $\mathrm{Xe+}$ & $\mathrm{Xe}_{2+}$ & $\mathrm{xe} 3+$ & & & $2 \overline{Z_{i}}$ & \\
\hline SPT-100, King & 0.888 & 0.110 & 0.002 & 0.734 & 0.257 & 0.009 & 0.866 & 0.921 & 1.064 & 0.980 \\
\hline P5. Gulczinski & 0.925 & $0.06:$ & 0.007 & 0.802 & 0.167 & 0.032 & 0.896 & 0.938 & 1.047 & 0.982 \\
\hline Average & 0.907 & $0.08 ! 1$ & 0.005 & 0.767 & 0.213 & 0.020 & 0.880 & 0.929 & 1.056 & 0.981 \\
\hline
\end{tabular}

Table 1 - Xenon ion species fraction data as reported by $\mathrm{King}^{27}$ and Gulczinski ${ }^{28}$ from timeof-flight mass spectrostopy measurements. Species current fractions are computed, as are several summations that are used in the multiply-charged performance model.

\begin{tabular}{|c|c|c|c|c|c|c|c|c|c|c|c|}
\hline & \multirow[b]{2}{*}{$V d, V$} & \multirow[b]{2}{*}{ Id, A } & \multirow[b]{2}{*}{$\begin{array}{l}\text { Anode Mass } \\
\text { Flow, ng/s }\end{array}$} & \multirow[b]{2}{*}{$\begin{array}{l}\text { Anode } \\
\text { Isp, sec }\end{array}$} & \multirow[b]{2}{*}{$\begin{array}{c}\text { Anode } \\
\text { Efficiency }\end{array}$} & \multirow[b]{2}{*}{$\begin{array}{c}\text { Thrust, } \\
\mathrm{mN}\end{array}$} & \multicolumn{5}{|c|}{ Singly-Charged Model Predictions } \\
\hline & & & & & & & $\Delta V, V$ & i & $\begin{array}{l}\text { Anode } \\
\text { Isp, sec }\end{array}$ & $\begin{array}{c}\text { Anode } \\
\text { Efficiency }\end{array}$ & $\begin{array}{c}\text { Thrust, } \\
\mathrm{mN}\end{array}$ \\
\hline SPT-70 & 300 & 2.2 & 2.56 & 1593 & 0.47 & 40 & 134 & 0.15 & 1592 & 0.47 & 40 \\
\hline SPT-100 & 300 & 4.5 & $4.9 \overline{9}$ & 1734 & 0.53 & 85 & 103 & 0.19 & 1735 & 0.53 & 84 \\
\hline
\end{tabular}

Table 2 - Performance data for the SPT-70 and SPT-100 with loss parameters that fit the singly-charged model to the performance data.

\begin{tabular}{|c|c|c|c|c|c|}
\hline \multicolumn{3}{|c|}{$P_{d}=50 \mathrm{~kW}$, Anorle $I_{s p}=2500 \mathrm{sec}$} & \multicolumn{3}{|c|}{$P_{d}=50 \mathrm{~kW}, I_{d}=100 \mathrm{~A}$} \\
\hline & $\begin{array}{c}\text { Singly-i harged } \\
\text { Mc del }\end{array}$ & $\begin{array}{c}\text { Multiply-Charged } \\
\text { Model }\end{array}$ & & $\begin{array}{c}\text { Singly-Charged } \\
\text { Model }\end{array}$ & $\begin{array}{c}\text { Multiply-Charged } \\
\text { Model }\end{array}$ \\
\hline$V_{d}, V$ & $\overline{4} \overline{j 9}$ & 4417 & $V_{d}, V$ & 500 & 500 \\
\hline$I_{d}, A$ & 103.9 & 119.9 & Anode $I_{s p}$ sec & 2622 & 2768 \\
\hline Anode Efficiency & $0 . \overline{56}$ & 0.64 & Anode Efficiency & 0.67 & 0.65 \\
\hline Thrust, $\mathrm{mN}$ & $26 \overline{89}$ & 2605 & Thrust, $\mathrm{mN}$ & 2590 & 2406 \\
\hline $\begin{array}{l}\text { Anode Mass Flow } \\
\text { Rate, } \mathrm{mg} / \mathrm{s}\end{array}$ & 109.7 & 120.6 & $\begin{array}{l}\text { Anode Mass Flow } \\
\text { Rate, } \mathrm{mg} / \mathrm{s}\end{array}$ & 100.7 & 88.6 \\
\hline
\end{tabular}

Table 3 - Model predictions of a $50 \mathrm{~kW}$ Hall thruster for an anode $I_{\mathrm{sp}}$ of $2500 \mathrm{~s}$ or a discharge current of $100 \mathrm{~A}$. Results from the singly-and multiply-charged models are presented, although the multiply-charged model is expected to be more accurate at high powers.

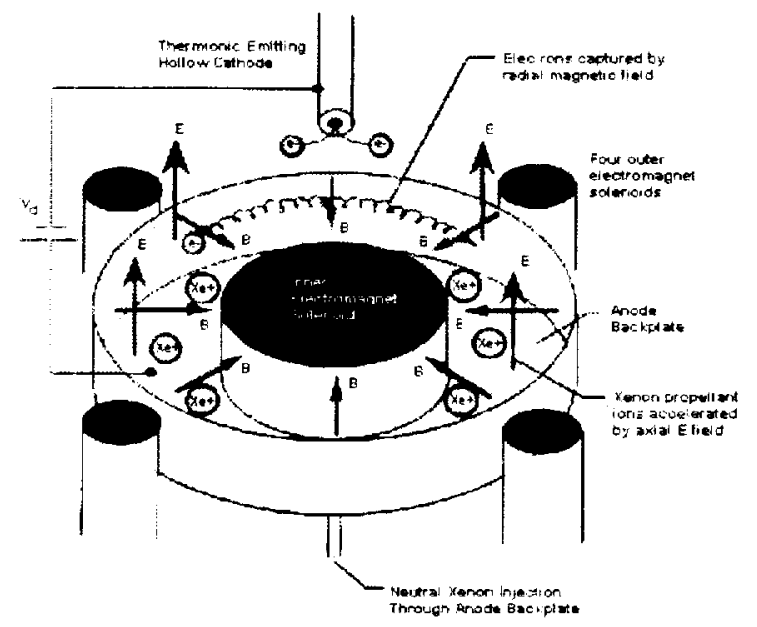

Figure 1 - The basic Hall thruster components showing the potential drop between the cathode and anode, the magnetic field circuit, and the closed electron drift induced by the crossed electric and majnetic fields. (Figure borrowed from Ref. 30 ). 


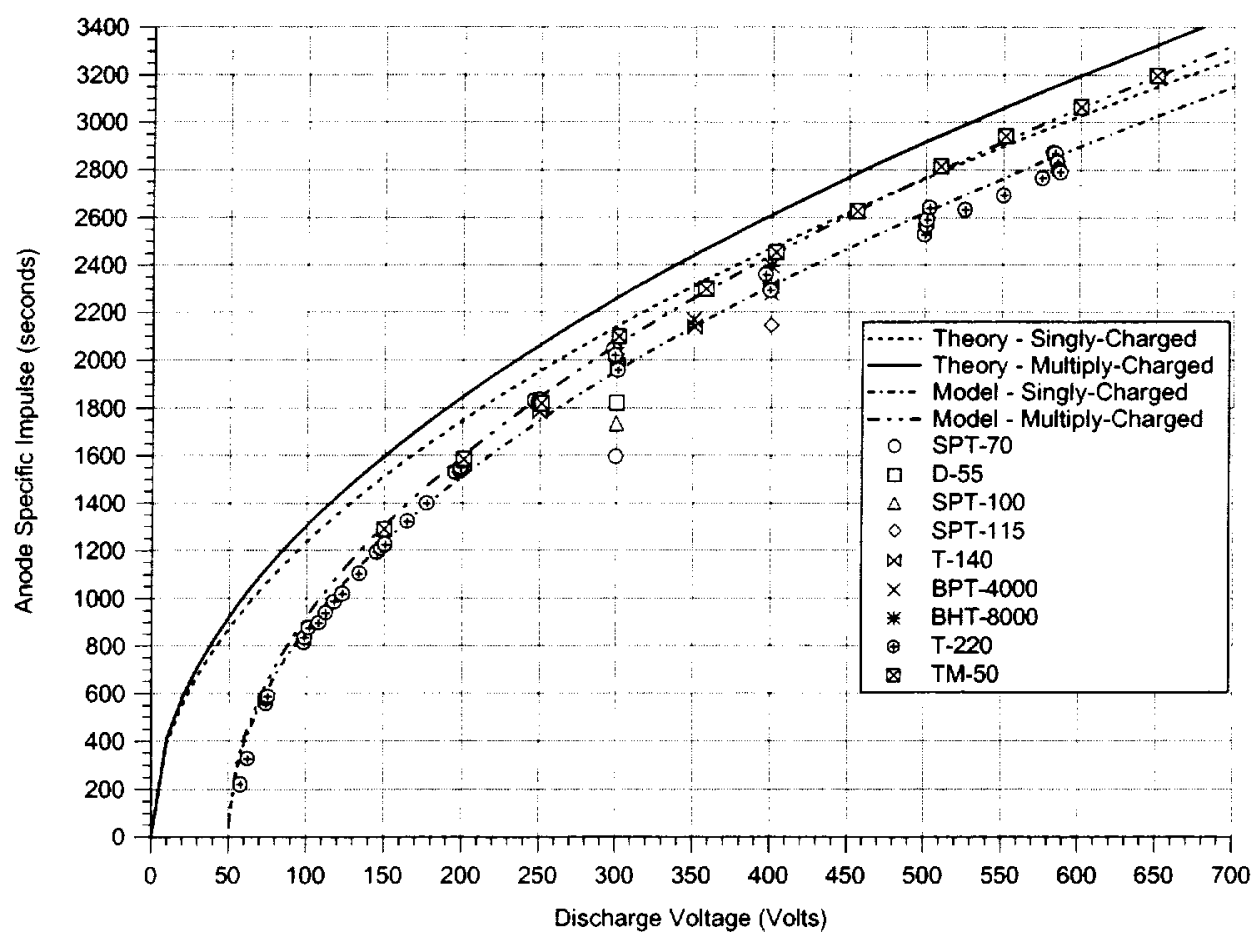

Figure 2 - Anode specific impulse versus discharge voltage. Theoretical and model curves are shown for a singly-or multiply-charged plasma. The voltage loss parameter is $\mathbf{5 0} \mathrm{V}$.

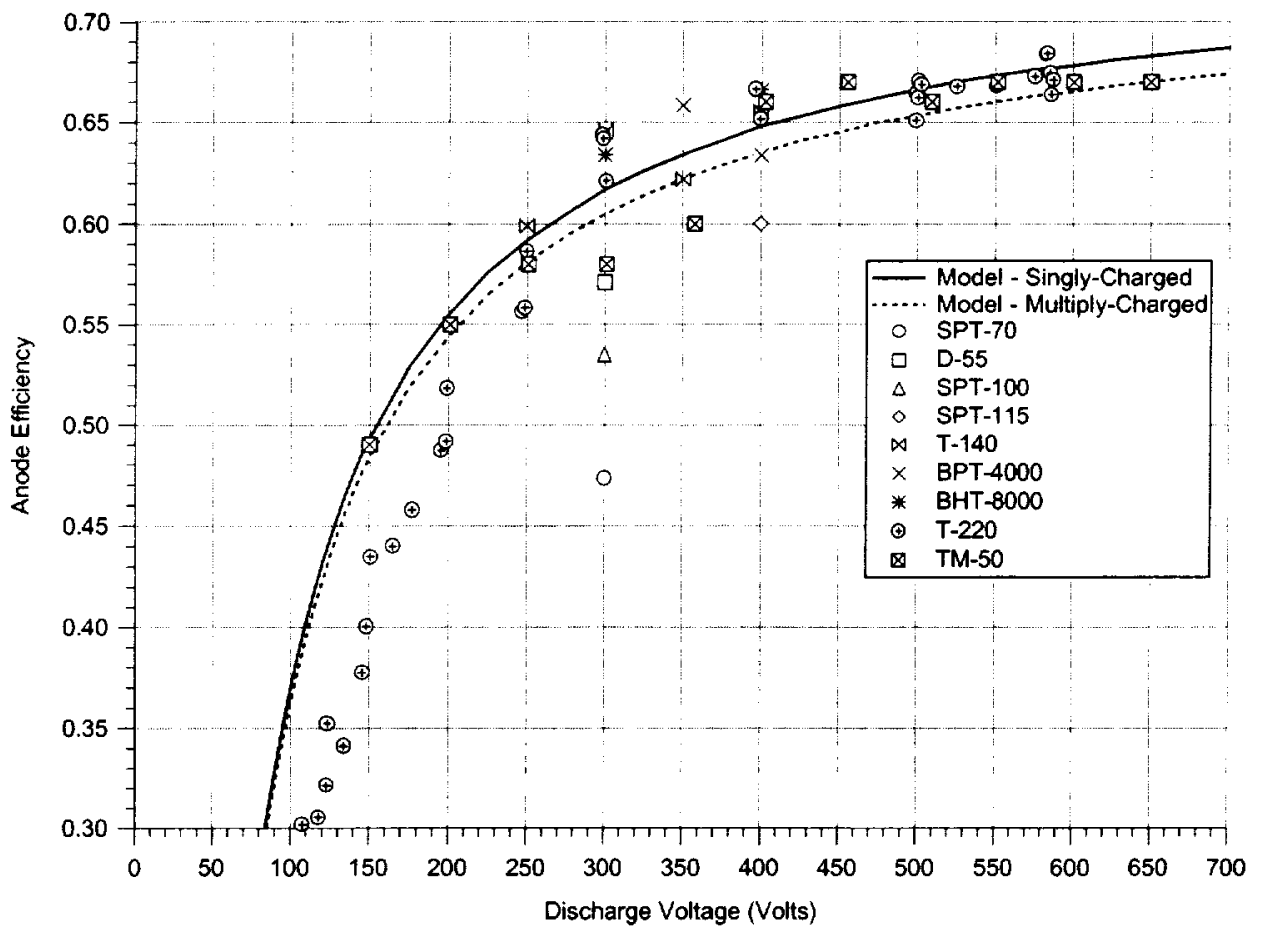

Figure 3 - Anode Efficiency versus discharge voltage. Model curves are shown for a singlyor multiply-charged plasma. The voltage loss parameter is $50 \mathrm{~V}$, and the electron loss parameter is 0.26 . 


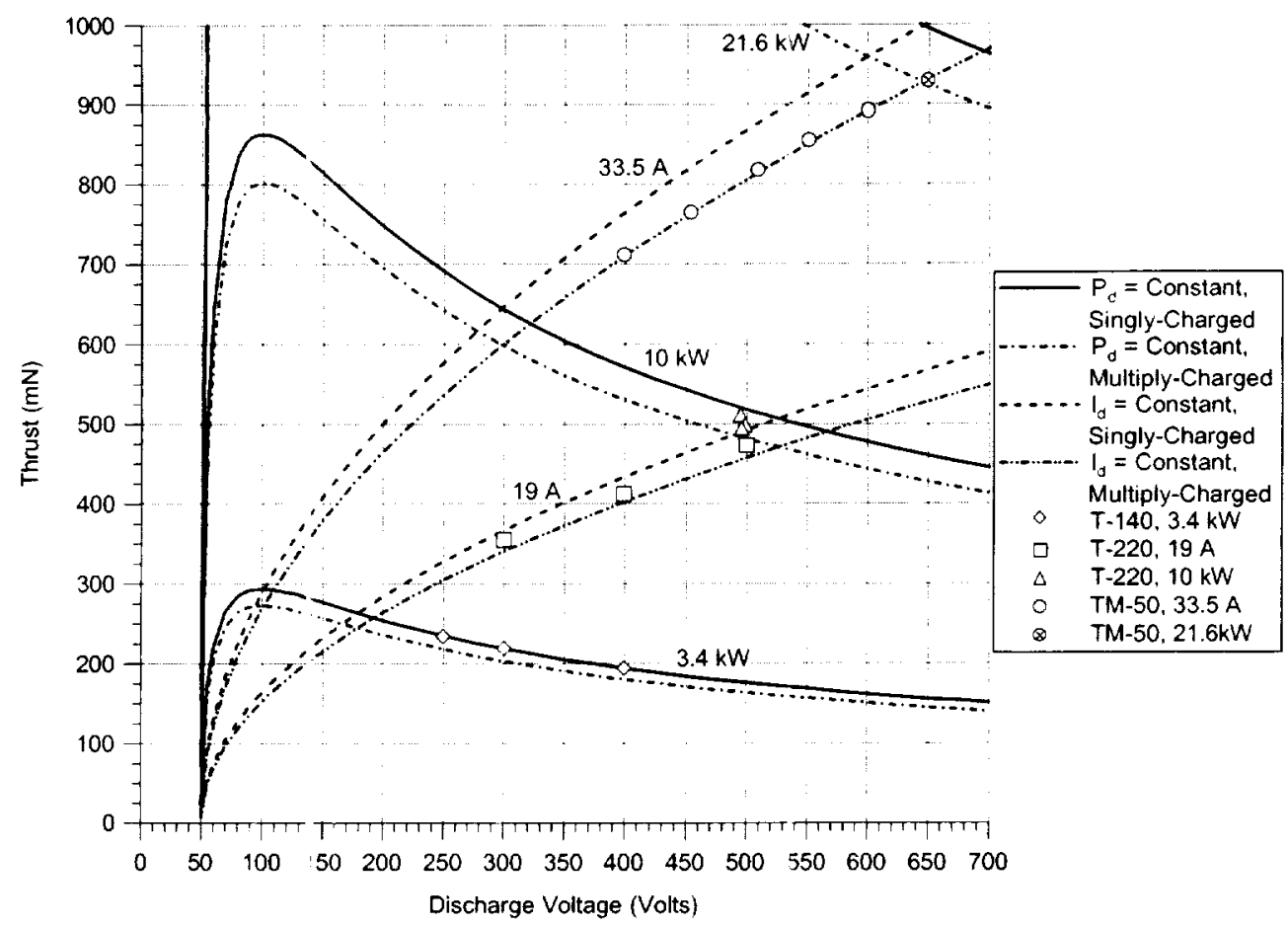

Figure 4 - Thrust versus discharge voltage. Constant power and constant current curves are shown for a singly- and multiply-charged plasma. The voltage loss parameter is $50 \mathrm{~V}$, and the electron loss parameter is 0.26 .

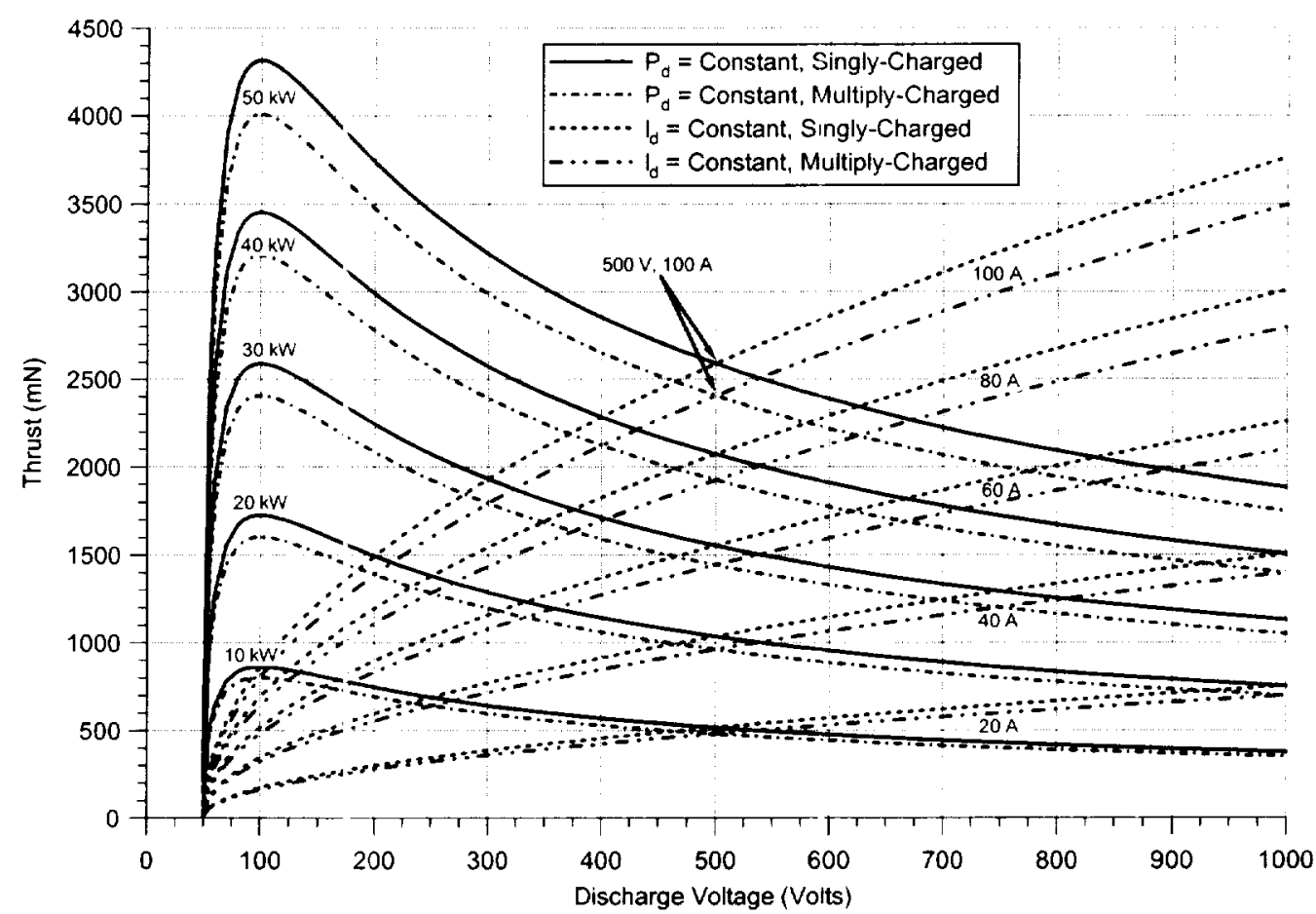

Figure 5 - Constant power and constant current curves for the singly-and multiply-charged performance models. The intersection of the $50 \mathrm{~kW}$ curve with the $100 \mathrm{~A}$ curve is indicated at $500 \mathrm{~V}$. 
\begin{tabular}{l|l|l|} 
1. AGENCY USE ONLY (Leave blank) & 2. REPORT DATE & 3. REPORT TYPE AND DATES COVERED
\end{tabular}

4. TITLE AND SUBTITLE
Technical Memorandum

A Hall Thruster Performance Model Incorporating the Effects of a Multiply-Charged Plasma

6. AUTHOR(S)

WU-755-B4-05-00

Richard R. Hofer and Robert S. Jankovsky

7. PERFOAMING ORGANIZATION NAME(S) AND ADDRESS(ES)

National Aeronautics and Space Administration

John H. Glenn Research Center at Lewis Field

Cleveland, Ohio 44135-3191

8. PERFORMING ORGANIZATION REPORT NUMBER

E-13066

9. SPONSORINGMONITORING AGENCY NAME(S) AND ADDRESS(ES)

10. SPONSORINGMONITORING AGENCY REPORT NUMBER

National Aeronautics and Space Administration

Washington, DC 20546-0001

NASA TM-2002-211214

AIAA-2001-3322

11. SUPPLEMENTARY NOTES

Prepared for the 37th Joint Propulsion Conference and Exhibit cosponsored by the AIAA, SAE, AIChE, and ASME, Salt Lake City, Utah, July 8-11, 2001. Richard R. Hofer, QSS Group, Inc.. 21000 Brookpark Road, Cleveland, Ohio 44135 and Robert S. Jankovsky, NASA Glenn Research Center. Responsible person, Robert Jankovsky, organization code 5430, 216-977-7515.

12a. DISTRIBUTION/AVALABILITY STATEMENT 12b. DISTRIBUTION CODE

Unclassified - Unlimited

Subject Category: 20

Distribution: Nonstandard

Available electronically at http://gltrs.grc,nasa.gov/GLTRS

This publication is available from the NASA Center for AeroSpace Information, 301-621-0390.

13. ABSTRACT (Maximum 200 words)

A Hall thruster performance model that predicts anode specific impulse, anode efficiency, and thrust is discussed. The model is derived as a function of a voltage loss parameter. an electron loss parameter, and the charge state of the plasma. Experimental data from SPT and TAL type thrusters up to discharge powers of $21.6 \mathrm{~kW}$ are used to determine the best fit for model parameters. General values for the model parameters are found, applicable to high power thrusters and irrespective of thruster type. Performance of a $50 \mathrm{~kW}$ thruster is calculated for an anode specific impulse of $2500 \mathrm{sec}$ or a discharge current of $100 \mathrm{~A}$.

\begin{tabular}{|c|c|c|c|}
\hline $\begin{array}{l}\text { 14. SUBJECT TERMS } \\
\text { Hall thruster; Model }\end{array}$ & & & $\begin{array}{l}\text { 15. NUMBER OF PAGES } \\
17 \\
\end{array}$ \\
\hline
\end{tabular}



, 